Article

\title{
Biosynthesis of Poly-(3-hydroxybutyrate) under the Control of an Anaerobically Induced Promoter by Recombinant Escherichia coli from Sucrose
}

\author{
Fangting Wu ${ }^{1,+}$, Ying Zhou ${ }^{2,+}$, Wenyu Pei ${ }^{1}$, Yuhan Jiang ${ }^{1}$, Xiaohui Yan ${ }^{3, * \mathbb{D}}$ and Hong Wu ${ }^{1, *}$ \\ 1 Tianjin Key Laboratory of Conservation and Utilization of Animal Diversity, College of Life Sciences, \\ Tianjin Normal University, Tianjin 300387, China; wft2021@163.com (F.W.); pwy13132023220@163.com (W.P.); \\ jyhleo@163.com (Y.J.) \\ 2 School of Chinese Materia Medica, Tianjin University of Traditional Chinese Medicine, Tianjin 301617, China; \\ zhouyingbiopharm@163.com \\ 3 State Key Laboratory of Component-Based Chinese Medicine, Tianjin University of Traditional Chinese Medicine, \\ Tianjin 301617, China \\ * Correspondence: yanxh@tjutcm.edu.cn (X.Y.); skywuhong@tjnu.edu.cn (H.W.) \\ + These authors contributed equally to this work.
}

check for

updates

Citation: Wu, F.; Zhou, Y.; Pei, W.;

Jiang, Y.; Yan, X.; Wu, H. Biosynthesis of Poly-(3-hydroxybutyrate) under the Control of an Anaerobically Induced Promoter by Recombinant Escherichia coli from Sucrose.

Molecules 2022, 27, 294. https:// doi.org/10.3390/molecules27010294 Academic Editors: Jing Han and Tao Chen

Received: 14 December 2021 Accepted: 31 December 2021 Published: 4 January 2022

Publisher's Note: MDPI stays neutral with regard to jurisdictional claims in published maps and institutional affiliations.

Copyright: (C) 2022 by the authors. Licensee MDPI, Basel, Switzerland. This article is an open access article distributed under the terms and conditions of the Creative Commons Attribution (CC BY) license (https:// creativecommons.org/licenses/by/ $4.0 /)$.

\begin{abstract}
Poly-(3-hydroxybutyrate) (PHB) is a polyester with biodegradable and biocompatible characteristics and has many potential applications. To reduce the raw material costs and microbial energy consumption during PHB production, cheaper carbon sources such as sucrose were evaluated for the synthesis of PHB under anaerobic conditions. In this study, metabolic network analysis was conducted to construct an optimized pathway for PHB production using sucrose as the sole carbon source and to guide the gene knockout to reduce the generation of mixed acid byproducts. The plasmid pMCS-sacC was constructed to utilize sucrose as a sole carbon source, and the cascaded promoter $\mathrm{P}_{3 \text { nirB }}$ was used to enhance PHB synthesis under anaerobic conditions. The mixed acid fermentation pathway was knocked out in Escherichia coli S17-1 to reduce the synthesis of byproducts. As a result, PHB yield was improved to $80 \%$ in $6.21 \mathrm{~g} / \mathrm{L}$ cell dry weight by the resulted recombinant Escherichia coli in a $5 \mathrm{~L}$ bed fermentation, using sucrose as the sole carbon source under anaerobic conditions. As a result, the production costs of PHB will be significantly reduced.
\end{abstract}

Keywords: polyhydroxyalkanoates; PHB; Escherichia coli; synthetic biology; anaerobic promoter

\section{Introduction}

Global warming concerns and environmental problems, such as microplastics and non-degradable plastics, are necessitating the transition from petrochemical-dependent industries into biorefineries and the production of polymers from renewable biomassbased resources such as microbes [1,2]. Researchers have emphasized the need to produce biodegradable bio-based plastics including polyhydroxyalkanoates (PHAs), polylatic acid (PLA), poly(butylene adipate-co-terephthalate) (PBAT), and so on, as a sustainable solution to the issues of plastic pollution and fuel depletion [3-6].

PHAs, as a family of biodegradable and biocompatible thermal polyesters, have attracted considerable attention to be developed as environmentally friendly bioplastics. The properties of PHAs are similar to those of conventional plastics [7]. Poly(3-hydroxybutyrate) (PHB) is the most common and well-studied member among the PHAs [8,9], and the favorable properties of PHB have led to its development and utilization as a biodegradable material in many fields such as wrapping films, bags, and bottles [10,11]. PHB can accumulate in various microorganisms from the natural environment, including Alcaligenes, Bacillus, and Pseudomonas [12,13]. Benefiting from the well-characterized genome and the wide availability of tools for genetic manipulation, Escherichia coli expressing acetyl-CoA acetyltransferase (PhaA), acetoacetyl-CoA reductase (PhaB), and PHA synthase (PhaC) has 
been extensively studied for PHB production, particularly for high-cell-density cultivation in bioreactors [14-17]. Process optimization and metabolic engineering strategies have facilitated a deeper understanding of PHB production by recombinant $E$. coli from renewable carbon sources. However, the high costs of fermentation substrates and the remarkable energy consumption during the fermentation processes had impeded the application of PHB as a bio-based plastic [18,19].

Synthesis of PHB via recombinant E. coli strain has received extensive attention, and numerous studies attempted to reduce the production cost of PHB to promote its commercialization [20-24]. For example, by optimizing the metabolic pathways of PHB, an engineered E. coli can use crude glycerol as the sole carbon source to produce PHB and reach a PHB content of $65 \%$ dry cell weight after fermentation [20]. Moreover, construction of the sucrose utilization pathway in an engineered $E$. coli XL1-Blue strain resulted in the production of $38 \mathrm{wt}$ \% PHB with $20 \mathrm{~g} / \mathrm{L}$ sucrose as the sole carbon source [21]. In addition to expanding the repertoire of the widely available and low-cost substrates such as sucrose, xylose, and glycerol, many studies also aimed at reducing the energy consumption in the fermentation processes, by utilizing hypoxic conditions that are more conducive to the accumulation of PHB [22-24].

Current research interest in PHB production mainly focuses on the application of metabolic engineering and synthetic biology strategies to increase PHB contents at a relatively low cost $[25,26]$. If the host strain can utilize the cheap and abundant carbon sources, the cost of PHB production will be significantly reduced, which is eventually beneficial for the popularization of PHB. Sucrose is an inexpensive and readily available substrate in sugarcane molasses and can be used as an alternative carbon source to glucose in E. coli $[27,28]$. The ability of sucrose utilization in an E. coli strain depends on the $\beta$-fructofuranosidase system, which is secreted into the culture medium where it can break down sucrose into glucose and fructose. When an E. coli strain did not have such enzymes, it could not use sucrose as carbon source. In order to produce PHB from sucrose in E. coli strains lacking sacC, both sucrose utilization and PHB biosynthesis pathways needed to be established. A sucrose utilization pathway was constructed in E. coli by expressing the $\beta$-fructofuranosidase (SacC) from Mannheimia succiniciproducens MBEL 55E [29]. By introducing the sacC gene, E. coli could convert sucrose into glucose and fructose [21]. In this way, the recombinant strain becomes a cost-effective and sustainable host to produce PHB and other materials.

The minimal cell growth rate, when the dissolved oxygen level cannot match the demand of cell growth, can be resolved with the inclusion of air compressors and agitation, but these efforts incur high energy consumption and additional costs during the fermentation process. E. coli can grow under microaerobic or anaerobic conditions; therefore, it is important to find efficient promoters that could respond to oxygen limitation to control gene expression under anaerobic conditions [30]. Anaerobic promoters that are inducible under a low dissolved oxygen level, such as $\mathrm{P}_{a d h E}$ and $\mathrm{P}_{v g b}$, could enhance PHB accumulation [31,32]. Indeed, PHB accumulation was increased by $18 \%$ under the control of the alcohol dehydrogenase promoter, $\mathrm{P}_{a d h E}$ [30]. The cascaded $v g b$ promoter, $\mathrm{P}_{8 v g b}$, improved PHB yield to more than $90 \%$ in recombinant E. coli under the low-aeration condition [33]. Furthermore, the bacterial cells are subjected to a low dissolved oxygen level and acidic byproducts. To overcome these challenges, E. coli strains with knocked out genes related to acid synthesis (for example, ackA-pta, poxB, and $l d h A$ ) have already been developed as a suitable host for PHB production under microaerobic conditions [34].

In this study, three E. coli strains (S17-1, DH5 $\alpha$, and Top10) were engineered to utilize sucrose as the sole carbon source using a $\beta$-galactosidase-expressing plasmid. Furthermore, the anaerobic promoter $\mathrm{P}_{\text {nirB }}$, which controls the expression of the nitrite reductase in E. coli, was selected to control the expression of the phaCAB operon in E. coli [35]. Their abilities to produce PHB under microaerobic conditions were compared. The genes involved in acid formation in E. coli were then knocked out in the most effective strain, and the anaerobic promoter $\mathrm{P}_{\text {nirB }}$ was cascaded to enhance $\mathrm{PHB}$ production under microaerobic conditions. 
Findings from this study offer a deeper understanding of PHB production in E. coli with anaerobic promoter expression systems.

\section{Results and Discussion}

\subsection{Metabolic Engineering Strategies for PHB Production from Sucrose}

The $\beta$-fructofuranosidase can break down sucrose into glucose and fructose. By engineering the pathway of the $\beta$-fructofuranosidase system, recombinant $E$. coli and Ralstonia eutropha have already been successfully modified to synthesize PHB with sucrose as the sole carbon source [21,36]. In this study, the $\beta$-fructofuranosidase-encoding gene was expressed in three different E. coli strains: S17-1, DH5 $\alpha$, and Top10, to compare their ability to produce PHB from sucrose in flask culture $(20 \mathrm{~g} / \mathrm{L}$ sucrose). Three mutant strains were all established by introducing the pBHR68 plasmid and the pMCS-sacC plasmid into these three E. coli strains. The pBHR68 plasmid contains the phaCAB genes from $R$. eutropha and the pMCS-sacC plasmid harbors the $\beta$-fructofuranosidase-encoding gene (sacC) from M. succiniciproducens (Figure 1).

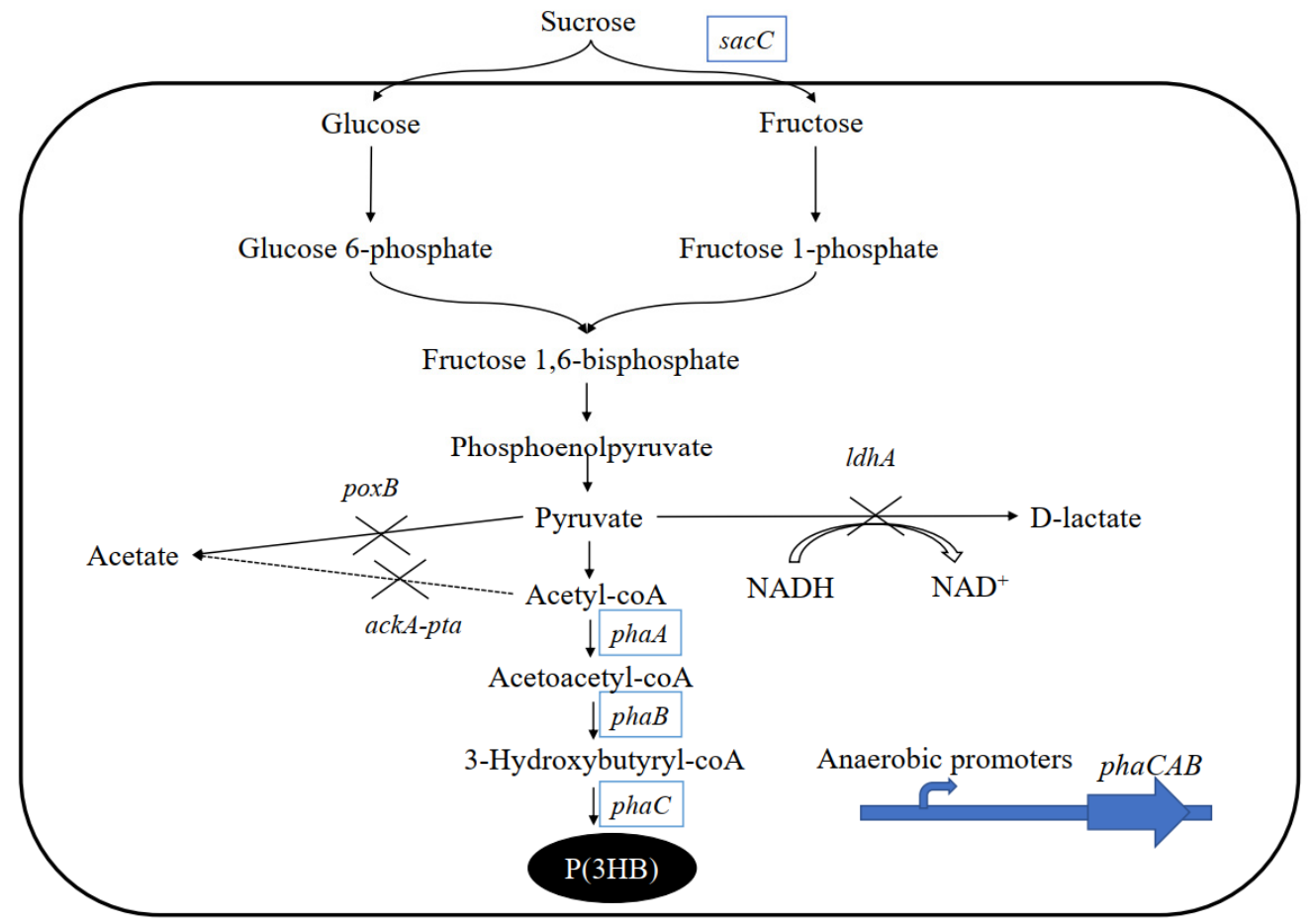

Figure 1. The biosynthetic pathway of PHB with flux distribution in E. coli using sucrose as a sole carbon source.

The concentrations of sucrose, glucose, and fructose were measured to determine sucrose utilization by the engineered pathway with the sacC gene in the flask culture. Sucrose was rapidly hydrolyzed into glucose and fructose initially, indicating that the sucrose utilization pathway had been successfully established in the host strains. The concentrations of remnant glucose were $3.40 \pm 0.39 \mathrm{~g} / \mathrm{L}(\mathrm{S} 17-1), 3.63 \pm 0.23 \mathrm{~g} / \mathrm{L}(\mathrm{DH} 5 \alpha)$, and $3.33 \pm 0.48 \mathrm{~g} / \mathrm{L}$ (Top10), while the concentrations of remnant fructose were $8.62 \pm 0.68 \mathrm{~g} / \mathrm{L}$ (S17-1), $8.55 \pm 0.57 \mathrm{~g} / \mathrm{L}(\mathrm{DH} 5 \alpha)$, and $8.79 \pm 0.36 \mathrm{~g} / \mathrm{L}$ (Top10) (Figure 2). The remnant fructose concentrations were relatively lower than that of glucose in all the three strains after cultivation. Thus, by expressing the $s a c C$ gene to hydrolyze sucrose, fructose was not utilized as efficiently as glucose in the recombinant E. coli strains (Figure 2A). This was consistent with the trend of sucrose utilization for the production of PHAs in a previous study [21]. During cultivation of the recombinant strain using sucrose, glucose was almost entirely utilized while fructose was not fully consumed. 


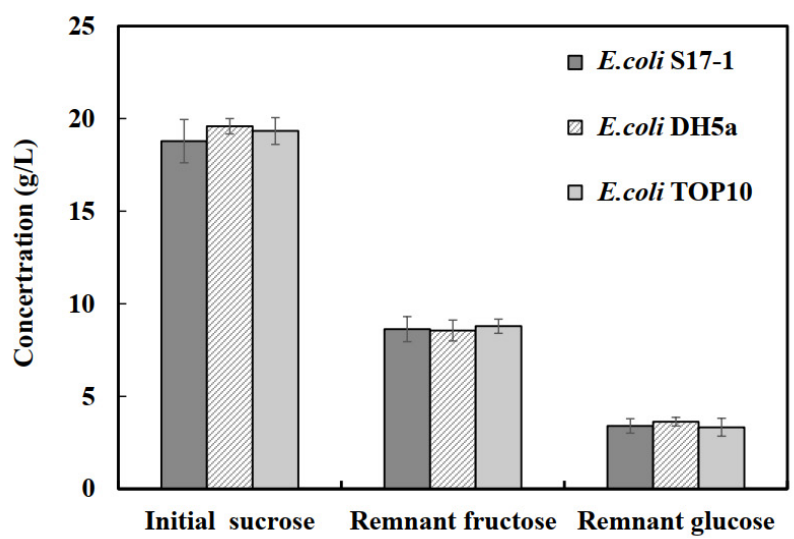

B

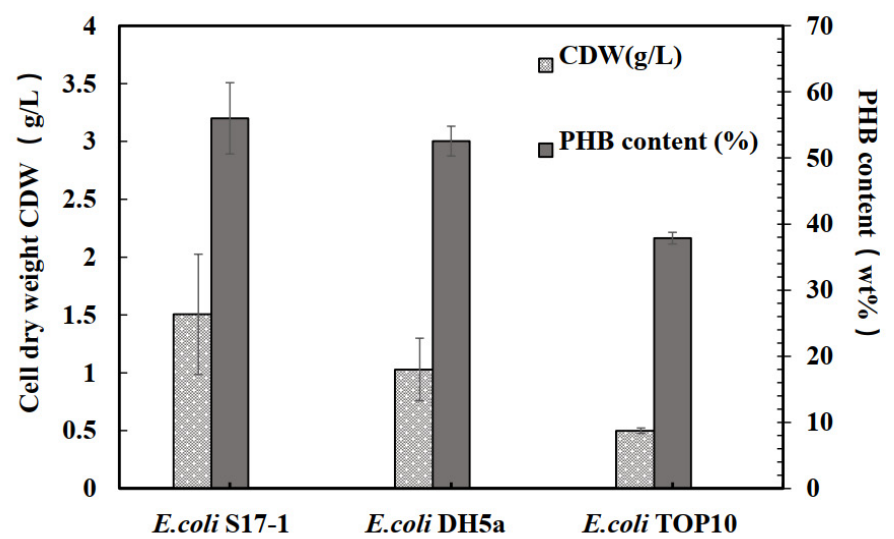

Figure 2. Sugar concentrations, cell dry weight (CDW), and PHB content in the culture flasks of the recombinant E. coli strains. (A) Concentrations of sucrose, glucose, and fructose were measured to investigate the utilization of sucrose; (B) CDW and PHB contents in the three recombinant strains of E. coli using sucrose as a substrate after $48 \mathrm{~h}$ cultivation.

To identify differences in PHB accumulation by the host strains, the CDW (cell dry weight) and intracellular PHB content were measured after cultivation for $48 \mathrm{~h}$. E. coli S17-1, DH5 $\alpha$, and TOP10 harboring plasmids $\mathrm{pBHR} 68$ and pMCS-sacC were cultivated in minimal medium (MM medium) with added $20 \mathrm{~g} / \mathrm{L}$ sucrose. Final CDW values were $1.51 \pm 0.52 \mathrm{~g} / \mathrm{L}(\mathrm{S} 17-1), 1.02 \pm 0.27 \mathrm{~g} / \mathrm{L}(\mathrm{DH} 5 \alpha)$, and $0.50 \pm 0.02 \mathrm{~g} / \mathrm{L}$ (Top10). All the three recombinant E. coli strains could accumulate more than $35 \%$ PHB. The final PHB contents (wt. \%) were $56 \%$ (S17-1), 53\% (DH5 $\alpha$ ), and 38\% (Top10). Among them, the highest PHB content was achieved by the recombinant S17-1 strain, while the lowest content was observed in Top10 (Figure 2B). S17-1 (pBHR68 and pMCS-sacC) yielded a maximal PHB content of $0.85 \mathrm{~g} / \mathrm{L}$ and was the most suitable host for PHB accumulation using sucrose as substrate. Utilization of sucrose by the recombinant strains could facilitate low-cost PHB production, which will increase economic competitiveness.

\subsection{Genetically Modified Promoter $P_{\text {nirB }}$ under Anaerobic Condition}

Microaerobic and anaerobic conditions were reported to reduce the costs for microbial production of PHB [37]. $\mathrm{P}_{\text {nirB }}$ is the promoter controlling the expression of the first gene of the nir operon in E. coli induced in anaerobic conditions. In order to achieve high PHB content under microaerobic conditions in E. coli, the nirB promoter was used to control the PHB biosynthesis operon $p h a \mathrm{CAB}$.

Assembly of repeated $\mathrm{P}_{\mathrm{vgb}}$ promoters was previously shown to create the strongest induction [33]; thus, this tandem repeat method was employed with the $\mathrm{P}_{\text {nirB }}$ promoter to improve cell growth under oxygen-limitation conditions. The Gibson assembly technique was used to generate three plasmids harboring different numbers of tandem repeats of the nirB promoter (Table 1). The $p h a C A B$ gene cluster was activated by transcription initiation of the anaerobic promoters $\mathrm{P}_{\text {nirB }}, \mathrm{P}_{2 \text { nirB }}$, and $\mathrm{P}_{3 \text { nirB }}$ to regulate $\mathrm{PHB}$ expression under anaerobic conditions (Figure 1). Comparison of the cascaded nirB promoters with the native promoter is shown in Figure 3. Differences in the sequence repeat may explain the likely variation in the ability of the promoters to induce downstream gene expression. Based on previous studies, PHB production is related to the transcription level of phaC [33]. The mRNA level of $p h a C$ was analyzed by RT-PCR as an indicator of $p h a C A B$ operon expression intensity. In recombinant $E$. coli with plasmid pBHR-P 3 nirB, the mRNA level of $p h a C$ was fivefold higher than that of the strain harboring the native promoter (Figure $3 \mathrm{~A}$ ). After cultivation for $24 \mathrm{~h}$ in anaerobic conditions, the efficacy of gene expression was improved with the increase in the repeat number of the promoter $\mathrm{P}_{\text {nirB }}$. In E. coli S17-1 harboring pBHR- 
$\mathrm{P}_{3 \text { nirB }}$, the mRNA transcription level of $p h a C$ was the highest, indicating that this strain may produce the highest content of PHB under anaerobic conditions (Figure 3A). Under the control of promoter $\mathrm{P}_{3 \mathrm{nir}}$, the transcription level of $p h a \mathrm{C}$ was significantly increased $(p<0.001)$.

Table 1. Escherichia coli strains and plasmids used in this study.

\begin{tabular}{|c|c|c|}
\hline Items & Descriptions & References \\
\hline \multicolumn{3}{|l|}{ Strains } \\
\hline E. coli S17-1 & recA pro hsdR RP4-2-Tc::Mu-Km::Tn7 integrated into the chromosome & [33] \\
\hline E. coli $\mathrm{TOP} 10$ & $\begin{array}{l}\text { F-morA } \Delta(\text { mrr-hsdRMS-mcrBC) } \varphi 80 \text { lacZ } \Delta \mathrm{M} 15 \Delta l a c X 74 \\
\text { recA1ara } \Delta 139 \Delta \text { (ara-leu)7697gallugalKrpsL(Starr)endA1 nup G }\end{array}$ & Industry MTA \\
\hline E. coli DH $5 \alpha$ & $\begin{array}{l}\mathrm{F}-\Phi 80 \text { lacZ } \Delta \mathrm{M} 15 \Delta(\text { lacZYA-argF)U169recA1endA1 hsdR17(rk-, mk+) phoA supE44 thi-1 } \\
\text { gyrA96 relA1 } \lambda-\end{array}$ & Industry MTA \\
\hline E. coli SA & E. coli S17-1 with the ackA-pta gene being knocked out & This study \\
\hline E. coli SAP & E. coli S17-1 with the ackA-pta and poxB genes being knocked out & This study \\
\hline E. coli SAPL & E. coli S17-1 with $a c k A-p t a$, poxB and $l d h A$ genes being knocked out & This study \\
\hline \multicolumn{3}{|l|}{ Plasmids } \\
\hline pBHR68 & $\begin{array}{l}\text { A pBluescript II SK-derivative containing } p h b C A B \text { operon from Ralstonia eutropha with } \\
\text { native promoter, } \mathrm{Amp}^{\mathrm{R}}\end{array}$ & [33] \\
\hline pBHR-P ${ }_{\text {nirB }}$ & $p B H R 68$ with the $p h b C A B$ operon under the control of the nirB anaerobic promoter & This study \\
\hline pBHR-P 2 nirB & $p B H R 68$ with the $p h b C A B$ operon under the control of the cascaded promoter 2 nir $B$ & This study \\
\hline pBHR-P 3 nirB & $p B H R 68$ with the $p h b C A B$ operon under the control of the cascaded promoter 3 nir $B$ & This study \\
\hline pBBR1MCS-2 & Broad-host-range plasmid, $\mathrm{Kan}^{\mathrm{R}}$ & Industry MTA \\
\hline pMCS-sacC & pBBR1MCS-2 with the sacC gene from M. succiniciproducens MBEL55E, Kan ${ }^{R}$ & This study \\
\hline
\end{tabular}

A

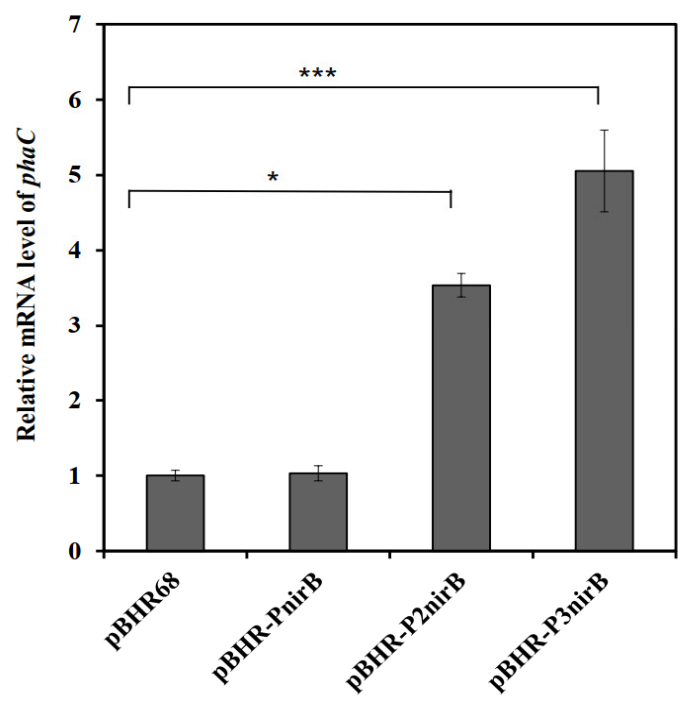

B

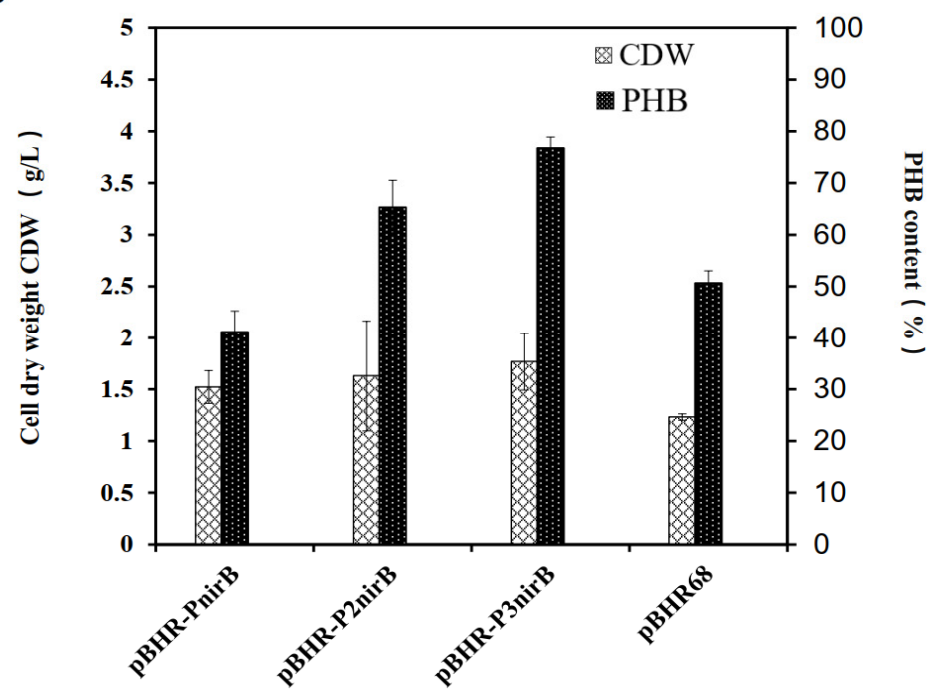

Figure 3. Transcription levels of $p h a C$ and PHB contents under different promoters. (A) Total RNA of four strains with different plasmids were isolated and real-time PCR assays for mRNA were performed using16S rRNA as the internal standard. Statistical analysis was performed by an unpaired two-tailed t-test. ${ }^{*} p<0.05$; ${ }^{* *} p<0.001$; (B) Cell dry weight and PHB contents of four strains with different promoters. In the $\mathrm{X}$-axis of $(\mathbf{A})$ and (B), plasmid names were both used to represent the strain information. $\mathrm{pBHR}-\mathrm{P}_{\text {nirB }}$ represented E. coli S17-1 (pBHR-P ${ }_{\text {nirB }}$ ), pBHR-P2nirB represented E. coli S17-1 (pBHR-P 2 nirB), pBHR-P3nirB represented E. coli S17-1 (pBHR-P 3 nirB), and pBHR68P represented E. coli S17-1 (pBHR68). Data are the average of three parallel experiments.

Consequently, pBHR-P $\mathrm{P}_{3 \text { nirB }}$ was selected to test cell growth and PHB accumulation in the recombinant $E$. coli S17-1 under anaerobic conditions. Under the control of the native 
promoter, the CDW of E. coli S17-1 exceeded $1.23 \mathrm{~g} / \mathrm{L}$, and the PHB content in the cells was $51 \%$. The E. coli S17-1 (pBHR-P ${ }_{\text {nirB }}$ ) strain accumulated $1.52 \mathrm{~g} / \mathrm{L} \mathrm{CDW}$ and contained over $41 \%$ PHB after cultivation for $48 \mathrm{~h}$. In contrast, E. coli S17-1 (pBHR-P 2 nirB) grew to $1.63 \mathrm{~g} / \mathrm{L}$ CDW and contained 65\% PHB. Recombinant E. coli S17-1 harboring the plasmid pBHR-P 3 nirB $\left(\right.$ three tandem repeats of $P_{\text {nirB }}$ ) grew to approximately $1.77 \mathrm{~g} / \mathrm{L} \mathrm{CDW}$ and contained $77 \%$ PHB (Figure 3B). Under the control of $P_{3 n i r B}$, the recombinant strain yielded the highest quantity of PHB after $48 \mathrm{~h}$ in shake flasks. Thus, the newly constructed promoter $\mathrm{P}_{3 \text { nirB }}$ was used in further experiments to control the expression of the phaCAB operon in anaerobic conditions.

\subsection{Disruption of the Mixed Acid Fermentation Pathway}

During the past few decades, microbial production of PHB under oxygen-limited conditions has attracted considerable attention because of the reduction in fermentation costs. Under anaerobic conditions, E. coli undertakes mixed acid fermentation via a pathway that produces lactate, succinate, acetate, formate, and ethanol, which decrease the carbon flux into PHB accumulation (Figure 1). It was previously reported that disruption of the mixed acid fermentation pathway could increase PHB accumulation in E. coli [30]. To investigate the possibility of a synergistic effect, a series of mixed acid fermentation mutants-E. coli SA, E. coli SAP, and E. coli SAPL-were constructed (Table 1). Genes ackA-pta and poxB, related to the formation of acetate, and the gene $l d h A$, related to the formation of D-lactate from pyruvate, were knocked out in E. coli S17-1, to reduce the formation of byproducts.

Initially, the resulting recombinant strains were cultivated in the MM medium supplemented with $20 \mathrm{~g} / \mathrm{L}$ glucose to produce PHB. After cultivation for $48 \mathrm{~h}$, E. coli SA harboring plasmid $\mathrm{pBHR}-\mathrm{P}_{3 \text { nirB }}$ reached a yield of 77\% PHB. E. coli SAP ( $\mathrm{pBHR}-\mathrm{P}_{3 \text { nirB }}$ ) grew better under anaerobic conditions, producing over $1.34 \mathrm{~g} / \mathrm{L} \mathrm{CDW}$ that contained $84 \%$ PHB, significantly higher than the $72 \%$ PHB produced by E. coli S17-1 (pBHR-P 3 nirB). PHB accumulated up to $87 \%$ of $1.90 \mathrm{~g} / \mathrm{L} \mathrm{CDW}$ in the E. coli SAPL ackA-pta, poxB, and $l d h A$ deletion mutant (Table 2). E. coli SAPL harboring the plasmid pBHR-P $P_{3 \text { nirB }}$ showed the highest PHB content after cultivation compared with the wild-type and other mutant strains.

Table 2. Bacterial growth and PHB production by different E. coli strains harboring $\mathrm{pBHR}-\mathrm{P}_{3 \text { nir } B}$ under an anaerobic condition.

\begin{tabular}{|c|c|c|c|}
\hline E. coli Strains ${ }^{a}$ & $\operatorname{CDW}(g / L)^{b}$ & PHB Concentration $(g / L){ }^{b}$ & PHB Content (wt.\%) ${ }^{b}$ \\
\hline E. coli $\mathrm{S} 17-1$ (pBHR-P 3 nirB $)$ & $1.52 \pm 0.16$ & $1.09 \pm 0.07$ & $72 \pm 3$ \\
\hline E. coli SA (pBHR-P 3 (nirB $)$ & $1.46 \pm 0.10$ & $1.12 \pm 0.12$ & $77 \pm 7$ \\
\hline E. coli SAP (pBHR-P $\left.{ }_{3 \text { nir }}\right)$ & $1.34 \pm 0.11$ & $1.13 \pm 0.15$ & $84 \pm 5$ \\
\hline E. coli SAPL (pBHR-P $\left.{ }_{3 \text { nir } B}\right)$ & $1.90 \pm 0.47$ & $1.65 \pm 0.36$ & $87 \pm 3$ \\
\hline
\end{tabular}

${ }^{a}$ Cells were cultivated in MM medium containing $20 \mathrm{~g} / \mathrm{L}$ glucose under an anaerobic condition for $48 \mathrm{~h}$

${ }^{b}$ Data are expressed as $\mathrm{M} \pm \mathrm{SD}$, in which $\mathrm{M}$ refers to mean and $\mathrm{SD}$ to standard deviation.

Next, the plasmid pMCS-sacC encoding $\beta$-fructofuranosidase was inserted into $E$. coli SAPL (pBHR-P 3nirB $_{3}$. The resulting recombinant strain was then cultivated in the MM medium, with added $20 \mathrm{~g} / \mathrm{L}$ sucrose as the carbon source, at $37^{\circ} \mathrm{C}$ for $48 \mathrm{~h}$; ampicillin and kanamycin were added to the medium to maintain the stability of the plasmids pBHR-P 3 nirB and pMCS-sacC. The sucrose was rapidly hydrolyzed, and the concentrations of glucose and fructose were observed during the cultivation. PHB accumulated up to $79 \%$, and CDW reached $7.71 \mathrm{~g} / \mathrm{L}$ in E. coli SAPL in MM medium sucrose in shake flasks (Table 3). These results indicated that E. coli SAPL (pBHR-P $\mathrm{P}_{3 \mathrm{nirB}}, \mathrm{pMCS}$-sacC) was more suitable and efficient for $\mathrm{PHB}$ production from sucrose as the carbon source under anaerobic culture conditions. 
Table 3. Bacterial growth and PHB production by E. coli SAPL (pBHR-P3nirB, pMCS-sacC) and E. coli S17-1 (pBHR68, pMCS-sacC) using sucrose as a carbon source under microaerobic conditions.

\begin{tabular}{|c|c|c|c|}
\hline E. coli Strains ${ }^{a}$ & $\operatorname{CDW}(g / L)^{b}$ & PHB Concentration $(g / L)^{b}$ & PHB Content (wt. \%) ${ }^{b}$ \\
\hline $\begin{array}{c}\text { E. coli SAPL } \\
\text { (pBHR-P } 3 \text { nirB, pMCS-sacC) }\end{array}$ & $1.71 \pm 0.27$ & $1.34 \pm 0.20$ & $79 \pm 6$ \\
\hline $\begin{array}{c}\text { E. coli S17-1 } \\
\text { (pBHR68, pMCS-sacC) }\end{array}$ & $1.57 \pm 0.51$ & $0.75 \pm 0.19$ & $49 \pm 8$ \\
\hline
\end{tabular}

${ }^{a}$ Cells were cultivated in the MM medium containing $20 \mathrm{~g} / \mathrm{L}$ sucrose under an anaerobic condition for $48 \mathrm{~h}$

${ }^{b}$ Data are expressed as $\mathrm{M} \pm \mathrm{SD}$, in which $\mathrm{M}$ refers to mean and $\mathrm{SD}$ to standard deviation.

\subsection{Production of PHB from Sucrose in Batch Fermentation}

Since the recombinant $E$. coli SAPL strain harboring the plasmids $\mathrm{pBHR}-\mathrm{P}_{3 \text { nirB }}$ and pMCS-sacC supported the highest production of PHB in flask cultures, it was used as the host strain for batch fermentation. E. coli SAPL (pBHR-P $\mathrm{P}_{3 \text { nirB }}$, pMCS-sacC) was cultured in a $5 \mathrm{~L}$ fermenter containing MM medium with $20 \mathrm{~g} / \mathrm{L}$ sucrose. The sucrose was completely hydrolyzed into glucose and fructose, which could be efficiently used for cell growth as well as PHB production, similar to the flask cultures (see Supplementary Material). The host strain grew well by utilizing sucrose as a carbon source and resulting in a final $\mathrm{CDW}$ of $7.71 \mathrm{~g} / \mathrm{L}$. After cultivation for $48 \mathrm{~h}$ under anaerobic conditions, $81 \%$ of PHB was accumulated and the final concentration of PHB at the end of batch fermentation was $6.21 \mathrm{~g} / \mathrm{L}$ (Figure 4). Cells of the fermentation strains were observed by SEM/TEM and were found to contain PHB inclusions (Figure 4), indicating that the sucrose pathway had been successfully constructed and $P_{3 \text { nirB }}$ was suitable to control PHB expression under a low level of oxygen. Further experiments on the optimization of fermentation conditions to enhance PHA synthesis may be beneficial for the commercial production of PHB.

$\mathbf{A}$

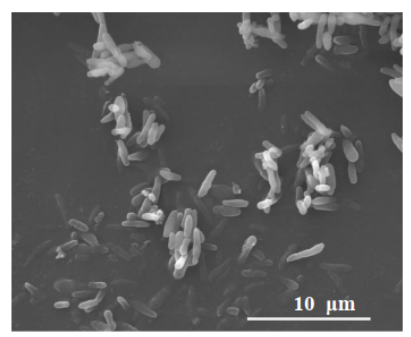

B

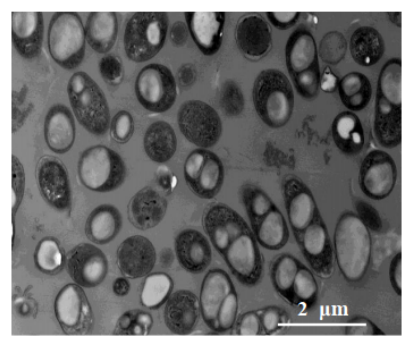

C

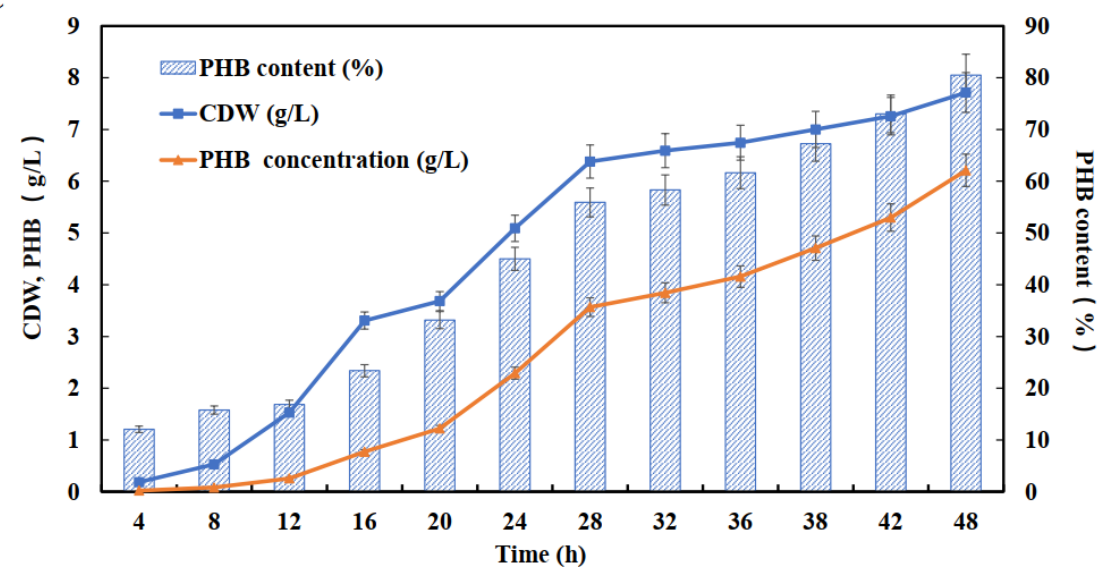

Figure 4. Bacterial growth and PHB production by E. coli SAPL harboring plasmids $\mathrm{pBHR}-\mathrm{P}_{3 \text { nirB }}$, pMCS-sacC under anaerobic conditions. (A) SEM micrographs of recombination strain; (B) TEM micrographs of recombination strain; (C) CDW, $\mathrm{PHB}$ concentration, and $\mathrm{PHB}$ content of recombination strain cultivated in the MM medium containing sucrose as a carbon source at $37^{\circ} \mathrm{C}$ for $48 \mathrm{~h}$. 


\section{Materials and Methods}

\subsection{Bacterial Strains and Plasmids}

All bacterial strains and plasmids used in this study are listed in Table 1. Three E. coli strains, S17-1, DH5 $\alpha$, and Top10, were selected as the host strains based on previous studies [21,33], to test their ability in PHB production from sucrose. E. coli is commonly used for genetic recombination, and the genes ackA-pta, poxB , and $l d h A$ related to mixed acid fermentation were knocked out by the one-step disruption method [38]. The homologous sequence (39 bp) upstream and downstream of each target gene and the kanamycin resistance gene (Kan) as a selection marker flanked by FLP recognition target sites were amplified by PCR to replace the target fragment on the chromosome. The Kan gene was then eliminated with the help of plasmid pCP20 expressing the FLP recombinase. The resulting deletions were confirmed by DNA sequencing. Three mutant strains (E. coli SA, E. coli SAP, and E. coli SAPL) with one gene knockout individually or all three genes knocked out together were constructed in this study (Table 1).

Genes encoding PHB synthesis operon phaCAB from Ralstonia eutropha and SacC from M. succiniciproducens MBEL55E were cloned into plasmids pBHR68 and pBBR1MCS-2, respectively. The construction of plasmids included vector isolation, DNA amplification of genes, restriction enzyme digestion, and other molecular cloning procedures. The anaerobic promoter $\mathrm{P}_{\text {nirB }}$ was cloned from the genomic DNA of $E$. coli extracted by the QIAamp DNA Mini Kit (Qiagen, Hilden, Germany). The PCR program comprised an initial denaturation at $94{ }^{\circ} \mathrm{C}$ for $3 \mathrm{~min}$, followed by 30 cycles of denaturation at $94{ }^{\circ} \mathrm{C}$ for $30 \mathrm{~s}$, annealing at $55{ }^{\circ} \mathrm{C}$ for $30 \mathrm{~s}$, and extension at $72{ }^{\circ} \mathrm{C}$ for $2 \mathrm{~min}$. The amplified sequence was tested for purity and size by $1 \%$ agarose gel electrophoresis. Genomic DNA was quantified with a NanoDrop 2000 spectrophotometer and used as the template to finish the promoter PCR. Cascaded promoter $\mathrm{P}_{\text {nirB }}$ was obtained by the Gibson assembly technique.

\subsection{Culture Medium and Growth Conditions}

Luria-Bertani (LB) medium ( $\mathrm{pH} 7.2$ ), used for DNA manipulations and plasmid construction, contained (per liter) $10 \mathrm{~g}$ tryptone, $5 \mathrm{~g}$ yeast extract, and $5 \mathrm{~g} \mathrm{NaCl}$. Strains were cultured in LB medium at $\mathrm{pH} 7.2$ and $37^{\circ} \mathrm{C}$. When antibiotic selection was required during cultivation, ampicillin $(100 \mu \mathrm{g} / \mathrm{mL})$, kanamycin $(50 \mu \mathrm{g} / \mathrm{mL})$, or chloramphenicol $(30 \mu \mathrm{g} / \mathrm{mL})$ were added to the medium depending on the plasmids.

The MM medium was used for PHB production in flask cultures and batch fermentations. This medium ( $\mathrm{pH}$ 6.8) contained (per liter) $\left(\mathrm{NH}_{4}\right)_{2} \mathrm{SO}_{4} 2.0 \mathrm{~g}, \mathrm{MgSO}_{4} 0.2 \mathrm{~g}$, $\mathrm{Na}_{2} \mathrm{HPO}_{4} \cdot 12 \mathrm{H}_{2} \mathrm{O} 9.65 \mathrm{~g}, \mathrm{KH}_{2} \mathrm{PO}_{4} 1.5 \mathrm{~g}$, trace metal solution I $10 \mathrm{~mL}$, and trace metal solution II $1 \mathrm{~mL}$ [39]. Trace metal solution contained $\mathrm{FeSO}_{4}, \mathrm{CaCl}_{2}, \mathrm{ZnSO}_{4} \cdot 7 \mathrm{H}_{2} \mathrm{O}, \mathrm{MnSO}_{4} \cdot 4 \mathrm{H}_{2} \mathrm{O}$, $\mathrm{CuSO}_{4} \cdot 5 \mathrm{H}_{2} \mathrm{O}$, and $\left(\mathrm{NH}_{4}\right)_{6} \mathrm{Mo}_{7} \mathrm{O}_{24} \cdot 4 \mathrm{H}_{2} \mathrm{O}$ and was sterilized separately. For PHB production, glucose $(20 \mathrm{~g} / \mathrm{L})$ or sucrose $(20 \mathrm{~g} / \mathrm{L})$ was added into the medium as the carbon source. Glucose was sterilized at $115^{\circ} \mathrm{C}$, and sucrose was sterilized using a $0.22 \mu \mathrm{m}$ filter.

Seed cultures for flask fermentation were first prepared in LB medium incubated at $37^{\circ} \mathrm{C}$ overnight in a rotary shaker at $200 \mathrm{rpm}$, and $1 \mathrm{~mL}$ of this overnight culture was then used to inoculate $100 \mathrm{~mL}$ MM medium. Aerobic growth was conducted using a $500 \mathrm{~mL}$ shake flask without baffles containing $100 \mathrm{~mL}$ culture medium under vigorous agitation at $50 \mathrm{rpm}$ (Shanghai, China). Batch culture of the recombinant E. coli strains was performed at $37{ }^{\circ} \mathrm{C}$ in a $5 \mathrm{~L}$ fermenter (New Brunswick BioFlo310, MA, USA) containing $2 \mathrm{~L}$ MM medium plus $20 \mathrm{~g} / \mathrm{L}$ sucrose. Anaerobic conditions were measured by dissolved oxygen electrodes during fermentation.

\subsection{Real-Time Quantitative PCR}

To study the induction effects of different promoters, calibration of the real-time quantitative PCR (RT-PCR) was performed based on a previously reported method [40]. Total RNA of E. coli was isolated, and cDNA was synthesized using an RNAprep pure Cell/Bacteria Kit and a FastQuant RT Kit. The RT-PCR assay for mRNA was performed 
with SuperReal PreMix (SYBR Green), using 16S rRNA (primers 16S-F: CACACTGGAACTGAGACAC and 16S-R: CTTCTTCTGCGGGTAACG) as the inner standard.

\subsection{Electron Microscopy}

PHB particles were observed by scanning electron microscopy (SEM) and transmission electron microscopy (TEM) after fermentation. For SEM, E. coli cells were collected and fixed with $2.5 \%(v / v)$ glutaraldehyde, then washed with $0.1 \mathrm{M}$ phosphate-buffered saline (PBS). Next, $50 \%, 70 \%, 80 \%, 90 \%$, and $100 \%$ ethanol were used to wash the fixed samples, and the samples were then further dehydrated using 2-methylpropan-2-ol mixed with ethanol (1:1). After treatment with pure 2-methylpropan-2-ol, the prepared sample was lyophilized and examined by SEM. For TEM, E. coli cells were pelleted by centrifugation, washed twice with PBS, and then mixed with a pre-cooled fixative solution at $4{ }^{\circ} \mathrm{C}$ overnight. After rinsing with $0.1 \mathrm{M}$ phosphate buffer ( $\mathrm{pH} 7.0)$, the samples were fixed with a $1 \%$ osmium acid solution and dehydrated with graded ethanol solutions and acetone. The prepared sample was sliced using a Leica Ultracut $S$ ultramicrotome and was visualized using a Talos F200X transmission electron microscope (Thermo Fisher Scientific, Waltham, MA, USA).

\subsection{Analytical Procedures}

Polymers were purified from the recombinant $E$. coli strains that were cultivated in MM supplemented with $20 \mathrm{~g} / \mathrm{L}$ sucrose. Briefly, cells were harvested by centrifugation at $10,000 \times g$ and $4{ }^{\circ} \mathrm{C}$ for $10 \mathrm{~min}$ and washed twice with distilled water. Cell dry weight (CDW) was measured after the cell pellets were lyophilized for more than $12 \mathrm{~h}$. Methanolysis was performed by adding $2 \mathrm{~mL} \mathrm{CH} 3 \mathrm{OH} / \mathrm{H}_{2} \mathrm{SO}_{4}$ with benzoic acid and $2 \mathrm{~mL} \mathrm{CHCl}$ to the samples and incubating at $100{ }^{\circ} \mathrm{C}$ for $4 \mathrm{~h}$. After cooling to room temperature and adding $1 \mathrm{~mL} \mathrm{ddH_{2 }} \mathrm{O}$ for stratification, the organic phase containing methyl-3-hydroxyalkanoates was analyzed by gas chromatography (GC) using a Spectra System P2000 (Thermo Separation, MA, USA) to measure the PHB content. GC was conducted using an HP-5 column $(30 \mathrm{~m}, 0.25 \mathrm{~mm})$ and a flame-ionization detector. Pure PHB was used as a standard sample for the GC based on a previous study [33].

To study the concentrations of sucrose, glucose, and fructose during batch fermentation, the culture supernatant was filtered through a $0.2 \mu \mathrm{m}$ syringe filter and then analyzed by high-performance liquid chromatography (HPLC; 1260 infinity series; Agilent Technologies, CA, USA) equipped with RID Detectors (G1362A, Agilent Technologies, CA, USA) and an Aminex HPX-87H ion-exclusion column operating at $37^{\circ} \mathrm{C}$. Sulfuric acid at a concentration of $0.005 \mathrm{~N}$ was used at flow rate of $1 \mathrm{~mL} / \mathrm{min}$ as the mobile phase.

\section{Conclusions}

Engineering microbial host strains to produce PHAs in a more efficient and cheaper way is important for their application as an environmentally friendly alternative to traditional plastics. Considering the substrate and dependence of oxygen, development of recombinant $E$. coli strains to produce PHB from sucrose as the sole carbon source under anaerobic condition can reduce both source material costs and energy consumption [41-43]. All the substantial components, including cost for the raw materials, utilities, and waste disposal, should be taken into account while estimating the cost $[44,45]$. The cost of the carbon source was mainly related with the price of different feedstocks, which have been shown to account for approximately $40 \%$ of the total PHB production costs [45]. The use of cheap carbon sources such as sucrose instead of glucose contributes to the economic feasibility of the method. On the other hand, aeration during fermentation is a major contributing factor to the fermentation costs, and the energy consumed on aeration could be reduced by using the anaerobic promoters that drive the expression of key biosynthetic genes under anaerobic conditions $[33,45]$. Thus, the use of promoter $\mathrm{P}_{3 \text { nir }}$ could reduce the energy spent on compressed air, and the cost on feedstocks could be reduced by the utilization of sucrose, which is much cheaper than glucose, as the carbon resource. In this study, plasmid pMCSsacC was constructed to utilize sucrose through the expression of $\beta$-fructofuranosidase and 
the promoter $\mathrm{P}_{3 \text { nirB }}$ was used to control PHB synthesis under anaerobic conditions. The mixed acid fermentation pathway was knocked out in E. coli S17-1 to reduce the synthesis of byproducts, thus E. coli SAPL was obtained as the host strain.

In summary, the recombinant E. coli SAPL strain harboring plasmids $\mathrm{pBHR}-\mathrm{P}_{3 \text { nirB }}$ and pMCS-sacC developed in this study could successfully utilize sucrose and produce $80 \%$ of PHB under anaerobic conditions. After cultivation for $48 \mathrm{~h}$ under anaerobic conditions, the amount of PHB at the end of batch fermentation reached $6.21 \mathrm{~g} / \mathrm{L}$, and the cost of substrate and energy was reduced. Findings from the study demonstrated that the sucrose utilization pathway could be constructed by expressing the $\mathrm{sacC}$ gene and that the cascaded anaerobic promoter $\mathrm{P}_{3 \text { nir } B}$ could enhance $\mathrm{PHB}$ accumulation under a low level of oxygen. Using microorganisms that are capable of sucrose utilization under anaerobic conditions will be useful for establishing a cost-effective process for the production of PHB and other value-added chemicals.

Supplementary Materials: The following are available online, Figure S1: Concentrations of glucose and fructose in batch fermentation for PHB production.

Author Contributions: Data curation and writing-original draft preparation, F.W. and Y.Z.; methodology, W.P.; validation, Y.J.; supervision, funding acquisition, and writing-review and editing, X.Y. and H.W. All authors have read and agreed to the published version of the manuscript.

Funding: This research was funded by the Science and Technology Planning Project of Tianjin (18ZLZXZF00220) and the National Natural Science Foundation of China (81872779).

Institutional Review Board Statement: Not applicable.

Informed Consent Statement: Not applicable.

Data Availability Statement: The data presented in this study are available in the article.

Conflicts of Interest: The authors declare no conflict of interest.

Sample Availability: Samples of the bacteria are available from the authors.

\section{References}

1. Reichert, C.L.; Bugnicourt, E.; Coltelli, M.B.; Cinelli, P.; Lazzeri, A.; Canesi, I.; Braca, F.; Martinez, B.M.; Alonso, R.; Agostinis, L.; et al. Bio-Based Packaging: Materials, Modifications, Industrial Applications and Sustainability. Polymers 2020, $12,1558$. [CrossRef]

2. Garrison, T.F.; Murawski, A.; Quirino, R.L. Bio-Based Polymers with Potential for Biodegradability. Polymers $2016,8,262$. [CrossRef]

3. Li, M.; Wilkins, M.R. Recent advances in polyhydroxyalkanoate production: Feedstocks, strains and process developments. Int. J. Biol. Macromol. 2020, 156, 691-703. [CrossRef]

4. Lambert, S.; Wagner, M. Environmental performance of bio-based and biodegradable plastics: The road ahead. Chem. Soc. Rev. 2017, 46, 6855-6871. [CrossRef]

5. Su, S.; Kopitzky, R.; Tolga, S.; Kabasci, S. Polylactide (PLA) and Its Blends with Poly(butylene succinate) (PBS): A Brief Review. Polymers 2019, 11, 1193. [CrossRef]

6. Fu, Y.; Wu, G.; Bian, X.; Zeng, J.; Weng, Y. Biodegradation behavior of Poly(Butylene Adipate-Co-Terephthalate) (PBAT), Poly(Lactic Acid) (PLA), and their blend in freshwater with Sediment. Molecules 2020, 25, 3946. [CrossRef]

7. Chen, G.Q.; Jiang, X.R. Engineering bacteria for enhanced polyhydroxyalkanoates (PHA) biosynthesis. Synth. Syst. Biotechnol. 2017, 2, 192-197. [CrossRef]

8. McAdam, B.; Brennan Fournet, M.; McDonald, P.; Mojicevic, M. Production of Polyhydroxybutyrate (PHB) and factors impacting its chemical and mechanical characteristics. Polymers 2020, 12, 2908. [CrossRef]

9. Amadu, A.A.; Qiu, S.; Ge, S.; Addico, G.N.D.; Ameka, G.K.; Yu, Z.; Xia, W.; Abbew, A.W.; Shao, D.; Champagne, P.; et al. A review of biopolymer (Poly-beta-hydroxybutyrate) synthesis in microbes cultivated on wastewater. Sci. Total Environ. 2021, 756, 143729. [CrossRef]

10. Zheng, Y.; Chen, J.C.; Ma, Y.M.; Chen, G.Q. Engineering biosynthesis of polyhydroxyalkanoates (PHA) for diversity and cost reduction. Metab. Eng. 2020, 58, 82-93. [CrossRef]

11. Hermann, D.R.; Lilek, D.; Daffert, C.; Fritz, I.; Weinberger, S.; Rumpler, V.; Herbinger, B.; Prohaska, K. In situ based surfaceenhanced Raman spectroscopy (SERS) for the fast and reproducible identification of PHB producers in cyanobacterial cultures. Analyst 2020, 145, 5242-5251. [CrossRef] 
12. Urtuvia, V.; Villegas, P.; Gonzalez, M.; Seeger, M. Bacterial production of the biodegradable plastics polyhydroxyalkanoates. Int. J. Biol. Macromol. 2014, 70, 208-213. [CrossRef]

13. Mostafa, Y.S.; Alrumman, S.A.; Otaif, K.A.; Alamri, S.A.; Mostafa, M.S.; Sahlabji, T. Production and characterization of bioplastic by polyhydroxybutyrate accumulating erythrobacter aquimaris isolated from Mangrove Rhizosphere. Molecules 2020, 25, 179. [CrossRef]

14. Meng, D.C.; Chen, G.Q. Synthetic Biology of Polyhydroxyalkanoates (PHA). Adv. Biochem. Eng. Biotechnol. 2018, 162, 147-174. [CrossRef]

15. Tang, X.; Chen, E.Y. Chemical synthesis of perfectly isotactic and high melting bacterial poly(3-hydroxybutyrate) from bio-sourced racemic cyclic diolide. Nat. Commun. 2018, 9, 2345. [CrossRef]

16. Park, S.H.; Kim, G.B.; Kim, H.U.; Park, S.J.; Choi, J.I. Enhanced production of poly3hydroxybutyrate (PHB) by expression of response regulator DR1558 in recombinant Escherichia coli. Int. J. Biol. Macromol. 2019, 131, 29-35. [CrossRef]

17. Lin, J.H.; Lee, M.C.; Sue, Y.S.; Liu, Y.C.; Li, S.Y. Cloning of phaCAB genes from thermophilic Caldimonas manganoxidans in Escherichia coli for poly(3-hydroxybutyrate) (PHB) production. Appl. Microbiol. Biotechnol. 2017, 101, 6419-6430. [CrossRef]

18. Tan, D.; Wang, Y.; Tong, Y.; Chen, G.Q. Grand challenges for industrializing Polyhydroxyalkanoates (PHAs). Trends Biotechnol. 2021, 39, 953-963. [CrossRef]

19. Bedade, D.K.; Edson, C.B.; Gross, R.A. Emergent approaches to efficient and sustainable Polyhydroxyalkanoate Production Molecules 2021, 26, 3463. [CrossRef]

20. Ganesh, M.; Senthamarai, A.; Shanmughapriya, S.; Natarajaseenivasan, K. Effective production of low crystallinity Poly(3hydroxybutyrate) by recombinant E. coli strain JM109 using crude glycerol as sole carbon source. Bioresour. Technol. 2015, 192, 677-681. [CrossRef]

21. Sohn, Y.J.; Kim, H.T.; Baritugo, K.A.; Song, H.M.; Ryu, M.H.; Kang, K.H.; Jo, S.Y.; Kim, H.; Kim, Y.J.; Choi, J.I.; et al. Biosynthesis of polyhydroxyalkanoates from sucrose by metabolically engineered Escherichia coli strains. Int. J. Biol. Macromol. 2020, 149, 593-599. [CrossRef]

22. Takahashi, R.Y.U.; Castilho, N.A.S.; Silva, M.; Miotto, M.C.; Lima, A.O.S. Prospecting for Marine Bacteria for Polyhydroxyalkanoate production on low-cost substrates. Bioengineering 2017, 4, 60. [CrossRef]

23. Inan, K.; Sal, F.A.; Rahman, A.; Putman, R.J.; Agblevor, F.A.; Miller, C.D. Microbubble assisted polyhydroxybutyrate production in Escherichia coli. BMC Res. Notes 2016, 9, 338. [CrossRef]

24. Izaguirre, J.K.; da Fonseca, M.M.R.; Fernandes, P.; Villaran, M.C.; Castanon, S.; Cesario, M.T. Upgrading the organic fraction of municipal solid waste to poly(3-hydroxybutyrate). Bioresour. Technol. 2019, 290, 121785. [CrossRef]

25. Schilling, C.; Badri, A.; Sieber, V.; Koffas, M.; Schmid, J. Metabolic engineering for production of functional polysaccharides. Curr. Opin. Biotechnol. 2020, 66, 44-51. [CrossRef]

26. Cardoso, L.O.B.; Karolski, B.; Gracioso, L.H.; do Nascimento, C.A.O.; Perpetuo, E.A. Increased P3HB accumulation capacity of methylorubrum sp. in response to discontinuous methanol addition. Appl. Biochem. Biotechnol. 2020, 192, 846-860. [CrossRef]

27. Sabri, S.; Nielsen, L.K.; Vickers, C.E. Molecular control of sucrose utilization in Escherichia coli W, an efficient sucrose-utilizing strain. Appl. Environ. Microbiol. 2013, 79, 478-487. [CrossRef]

28. Miranda De Sousa Dias, M.; Koller, M.; Puppi, D.; Morelli, A.; Chiellini, F.; Braunegg, G. Fed-Batch Synthesis of Poly(3hydroxybutyrate) and Poly(3-hydroxybutyrate-co-4-hydroxybutyrate) from Sucrose and 4-hydroxybutyrate Precursors by Burkholderia sacchari Strain DSM 17165. Bioengineering 2017, 4, 36. [CrossRef]

29. Lee, J.W.; Choi, S.; Kim, J.M.; Lee, S.Y. Mannheimia succiniciproducens phosphotransferase system for sucrose utilization. Appl. Environ. Microbiol. 2010, 76, 1699-1703. [CrossRef]

30. Wei, X.X.; Zheng, W.T.; Hou, X.; Liang, J.; Li, Z.J. Metabolic Engineering of Escherichia coli for Poly(3-hydroxybutyrate) Production under Microaerobic Condition. Biomed. Res. Int. 2015, 2015, 789315. [CrossRef]

31. Su, Y.; Li, X.; Liu, Q.; Hou, Z.; Zhu, X.; Guo, X.; Ling, P. Improved poly-gamma-glutamic acid production by chromosomal integration of the Vitreoscilla hemoglobin gene (vgb) in Bacillus subtilis. Bioresour. Technol. 2010, 101, 4733-4736. [CrossRef]

32. Membrillo-Hernandez, J.; Kwon, O.; De Wulf, P.; Finkel, S.E.; Lin, E.C. Regulation of adhE (encoding ethanol oxidoreductase) by the Fis protein in Escherichia coli. J. Bacteriol. 1999, 181, 7390-7393. [CrossRef]

33. Wu, H.; Wang, H.; Chen, J.; Chen, G.Q. Effects of cascaded vgb promoters on poly(hydroxybutyrate) (PHB) synthesis by recombinant Escherichia coli grown micro-aerobically. Appl. Microbiol. Biotechnol. 2014, 98, 10013-10021. [CrossRef]

34. Jian, J.; Zhang, S.Q.; Shi, Z.Y.; Wang, W.; Chen, G.Q.; Wu, Q. Production of polyhydroxyalkanoates by Escherichia coli mutants with defected mixed acid fermentation pathways. Appl. Microbiol. Biotechnol. 2010, 87, 2247-2256. [CrossRef]

35. Harborne, N.R.; Griffiths, L.; Busby, S.J.; Cole, J.A. Transcriptional control, translation and function of the products of the five open reading frames of the Escherichia coli nir operon. Mol. Microbiol. 1992, 6, 2805-2813. [CrossRef]

36. Park, S.J.; Jang, Y.A.; Noh, W.; Oh, Y.H.; Lee, H.; David, Y.; Baylon, M.G.; Shin, J.; Yang, J.E.; Choi, S.Y.; et al. Metabolic engineering of Ralstonia eutropha for the production of polyhydroxyalkanoates from sucrose. Biotechnol. Bioeng. 2015, 112, 638-643. [CrossRef]

37. Wei, X.X.; Shi, Z.Y.; Yuan, M.Q.; Chen, G.Q. Effect of anaerobic promoters on the microaerobic production of polyhydroxybutyrate (PHB) in recombinant Escherichia coli. Appl. Microbiol. Biotechnol. 2009, 82, 703-712. [CrossRef]

38. Datsenko, K.A.; Wanner, B.L. One-step inactivation of chromosomal genes in Escherichia coli K-12 using PCR products. Proc. Natl. Acad. Sci. USA 2000, 97, 6640-6645. [CrossRef] 
39. Wang, Y.; Wu, H.; Jiang, X.; Chen, G.Q. Engineering Escherichia coli for enhanced production of poly(3-hydroxybutyrate-co-4hydroxybutyrate) in larger cellular space. Metab Eng 2014, 25, 183-193. [CrossRef]

40. Schmittgen, T.D.; Livak, K.J. Analyzing real-time PCR data by the comparative C(T) method. Nat. Protoc. 2008, 3, 1101-1108. [CrossRef]

41. Sirohi, R.; Prakash Pandey, J.; Kumar Gaur, V.; Gnansounou, E.; Sindhu, R. Critical overview of biomass feedstocks as sustainable substrates for the production of polyhydroxybutyrate (PHB). Bioresour. Technol. 2020, 311, 123536. [CrossRef]

42. Amaro, T.; Rosa, D.; Comi, G.; Iacumin, L. Prospects for the Use of Whey for Polyhydroxyalkanoate (PHA) Production. Front. Microbiol. 2019, 10, 992. [CrossRef]

43. Getachew, A.; Woldesenbet, F. Production of biodegradable plastic by polyhydroxybutyrate (PHB) accumulating bacteria using low cost agricultural waste material. BMC Res. Notes 2016, 9, 509. [CrossRef]

44. Kim, B.S. Production of poly(3-hydroxybutyrate) from inexpensive substrates. Enzyme Microb. Technol. 2000, 27, 774-777. [CrossRef]

45. Kumar, L.R.; Kaur, R.; Tyagi, R.D.; Drogui, P. Identifying economical route for crude glycerol valorization: Biodiesel versus polyhydroxy-butyrate (PHB). Bioresour. Technol. 2021, 323, 124565. [CrossRef] 